\title{
Two novel oxy-fuel power cycles integrated with natural gas reforming and $\mathrm{CO}_{2}$ capture
}

\author{
Na Zhang ${ }^{\mathrm{a}, *}$, Noam Lior ${ }^{\mathrm{b}}$ \\ anstitute of Engineering Thermophysics, Chinese Academy of Sciences, Beijing 100080, PR China \\ ${ }^{\mathrm{b}}$ Department of Mechanical Engineering and Applied Mechanics, University of Pennsylvania, Philadelphia, PA 19104-6315, USA
}

Received 19 December 2006

\begin{abstract}
Two novel system configurations were proposed for oxy-fuel natural gas turbine systems with integrated steam reforming and $\mathrm{CO}_{2}$ capture and separation. The steam reforming heat is obtained from the available turbine exhaust heat, and the produced syngas is used as fuel with oxygen as the oxidizer. Internal combustion is used, which allows a very high heat input temperature. Moreover, the turbine working fluid can expand down to a vacuum, producing an overall high-pressure ratio. Particular attention was focused on the integration of the turbine exhaust heat recovery with both reforming and steam generation processes, in ways that reduce the heat transfer-related exergy destruction. The systems were thermodynamically simulated, predicting a net energy efficiency of 50-52\% (with consideration of the energy needed for oxygen separation), which is higher than the Graz cycle energy efficiency by more than 2 percentage points. The improvement is attributed primarily to a decrease of the exergy change in the combustion and steam generation processes that these novel systems offer. The systems can attain a nearly $100 \% \mathrm{CO}_{2}$ capture.
\end{abstract}

(C) 2007 Elsevier Ltd. All rights reserved.

Keywords: Novel power systems; Oxy-fuel cycles; Natural gas reforming; $\mathrm{CO}_{2}$ capture

\section{Introduction}

Greenhouse gas emissions, and carbon dioxide emissions in particular, have become an increasing concern in the power generation industry. Great efforts are devoted to research and development of innovative power systems with low $\mathrm{CO}_{2}$ emissions, generally grouped into three removal strategies [1-3]: (1) post-combustion decarbonization, (2) oxy-fuel power cycles, and (3) pre-combustion decarbonization. Each has some advantages and disadvantages, and they all decrease power generation efficiency and increase its cost.

Post-combustion decarbonization separates $\mathrm{CO}_{2}$ from the flue gases; it requires minimal modifications to the power

\footnotetext{
Abbreviations: CON; Condenser; HEX; Heat exchanger; HPST; Highpressure steam turbine; HPT; High-pressure gas turbine; HRSG; Heat recovery steam generator; LPT; Low-pressure gas turbine; PRE-REF; Pre-reformer; REF; Reformer.

*Corresponding author. Tel.: + 861082543030 ; fax: + 861062575913.

E-mail address: zhangna@mail.etp.ac.cn (N. Zhang).
}

cycle, but large gas quantities must be treated because $\mathrm{CO}_{2}$ is diluted by the nitrogen that entered with the introduced combustion air. Chemical absorption of the $\mathrm{CO}_{2}$ is considered to be the most suitable method for this case because of the low $\mathrm{CO}_{2}$ partial pressure [3,4]. To improve the absorption process with lower energy consumption and proper reaction speed, efforts are needed for the development of new solvents and optimization of the solvent compositions.

Oxy-fuel cycles are based on the close-to-stoichiometric combustion, where the fuel is burned with enriched oxygen (produced in an air separation unit) and recycled flue gas. The combustion is accomplished in absence of the large amounts of nitrogen that air would have brought in if enriched oxygen was not used, and produces only $\mathrm{CO}_{2}$ and $\mathrm{H}_{2} \mathrm{O}$. $\mathrm{CO}_{2}$ separation is accomplished by condensing water from the flue gas and therefore requires only a modest amount of energy. At the same time, however, a relatively large amount of energy, $7-10 \%$ of the total system input, is needed for the oxygen production. The main (and the 


\section{Nomenclature}

$H \quad$ enthalpy $(\mathrm{kJ} / \mathrm{kg})$

LMTD logarithmic mean temperature difference $\left({ }^{\circ} \mathrm{C}\right)$

$m \quad$ mass flow rate $(\mathrm{kg} / \mathrm{s})$

$P \quad$ pressure (bar)

$T$ temperature $\left({ }^{\circ} \mathrm{C}\right)$

$Q \quad$ heat duty (MW)

$\Delta T_{\min }$ minimal heat transfer temperature difference $\left({ }^{\circ} \mathrm{C}\right)$

Subscripts

$1,2, \ldots 30$ states on the system flow sheet

\section{Components}

CON Condenser

HEX Heat exchanger

HPST High pressure steam turbine

HPT High pressure gas turbine

HRSG Heat recovery steam generator

LPT Low pressure gas turbine

PRE-REF Pre-reformer

REF Reformer recycled) working fluid commonly used is either $\mathrm{CO}_{2}$ or $\mathrm{H}_{2} \mathrm{O}$. The systems using $\mathrm{CO}_{2}$ include the MATIANT cycle [5,6], COOPERATE cycle [7,8] or COOLENERG cycle [9], and we have proposed systems integrated with LNG cold exergy utilization $[10,11]$. Those using $\mathrm{H}_{2} \mathrm{O}$ as the working fluid include the Water cycle [12,13] developed by Clean Energy Systems (CES), the Graz cycle [14], and others [15]. To reduce the oxygen production efficiency penalty, new technologies have been developed, such as chemical looping combustion [16-18] and the AZEP concept [19,20]. Kvamsdal et al. [21] made a quantitative comparison of various cycles with respect to plant efficiency and $\mathrm{CO}_{2}$ emissions, showing that the adoption of these new technologies promises improved performance because they require no additional energy for oxygen production, but they are still under development.

Pre-combustion decarbonization is accomplished by conversion of the fuel to $\mathrm{CO}$ - and $\mathrm{H}_{2}$-enriched syngas that finally produces hydrogen fuel by a shift process in which the $\mathrm{CO}$ is converted to $\mathrm{CO}_{2}$, that is then separated out [1,2,22-24]. Because the unconverted methane generates $\mathrm{CO}_{2}$-rich exhausts, a high methane conversion rate (usually above $94 \%$ ) is claimed. Depending on the operational conditions (mainly the pressure and $\mathrm{CO}_{2}$ concentration), the $\mathrm{CO}_{2}$ removal can be accomplished by either physical or chemical absorption.

A gas turbine with steam reforming is called a chemically recuperated gas turbine (CRGT) [25-27]. The basic concept is the recovery of turbine exhaust heat for improving the fuel heating value by methane conversion to $\mathrm{H}_{2}$ and $\mathrm{CO}$. Different from the situation in the plants with pre-combustion decarbonization, it is not essential in the CRGT cycle to obtain an elevated conversion rate because the unconverted reactants are all used as fuel.

In this paper, we propose and analyze a novel family of systems with low $\mathrm{CO}_{2}$ emissions, aimed at reducing the $\mathrm{CO}_{2}$ capture penalty. They integrate natural gas reforming technology with an oxy-fuel semi-closed power cycle. The steam reforming process is similar to that in the CRGT cycle, where only a medium conversion rate of methane is obtained with the available turbine discharge temperature; the fact that the $\mathrm{CO}_{2}$ capture is aided by oxy-fuel combustion is an important advantage. Water is employed as the main working fluid. Particular attention has been paid to the integration of the turbine heat recovery with both the reforming and the steam generation process.

\section{The natural gas reforming process}

Chemical recuperation is considered as one of the innovative concepts to improve the performance of natural gas-fired gas turbine cycles [25-27]. The natural gas reforming process absorbs heat from the turbine exhaust to produce hydrogen, thus converting some of the turbine exhaust heat into the reforming products heating value. One of the other key advantages of CRGT cycles is their potential for $\mathrm{NO}_{x}$ emissions estimated to be as low as $1 \mathrm{ppm}[26,27]$, compared with $25 \mathrm{ppm}$ in the steam-injected gas turbine (STIG) cycle. A comparison [27] concluded that the basic CRGT cycle (without intercooling or reheat) has a thermal efficiency higher than the STIG cycle and the simple gas turbine cycle, but not as high as the combined cycle.

The reforming process involves the following main reactions [2]:

$$
\begin{aligned}
& \mathrm{CH}_{4}+\mathrm{H}_{2} \mathrm{O} \leftrightarrow \mathrm{CO}+3 \mathrm{H}_{2} \quad \Delta H=206.11 \mathrm{~kJ} / \mathrm{mol} \mathrm{CH}_{4}, \\
& \mathrm{CO}+\mathrm{H}_{2} \mathrm{O} \leftrightarrow \mathrm{CO}_{2}+\mathrm{H}_{2} \quad \Delta H=-41.17 \mathrm{~kJ} / \mathrm{mol} \mathrm{CO}, \\
& \mathrm{C}_{n} \mathrm{H}_{m}+n \mathrm{H}_{2} \mathrm{O} \rightarrow n \mathrm{CO}+(m / 2+n) \mathrm{H}_{2} .
\end{aligned}
$$

The first reaction is the methane reforming. It is highly endothermic and the methane conversion rate is a function of temperature, pressure, and steam/methane ratio [24]. Low pressure, high temperature and high steam consumption increase conversion. For power cycles adopting precombustion decarbonization, a methane conversion rate higher than $94-95 \%$ is needed for over $90 \% \mathrm{CO}_{2}$ removal, 
according to Lozza and Chiesa [24]. The typical gas turbine exhaust temperature, $550-600{ }^{\circ} \mathrm{C}$, is not sufficiently high for such high conversion rate even under low pressure. Therefore supplementary firing [23] or auto thermal reforming (ATR) [22], in which a fraction of the natural gas is used as fuel, is necessary to raise the turbine exhaust temperature level.

The second reaction is known as the shift reaction. The third one is the reforming of heavier hydrocarbons, which is usually considered irreversible [2].

The situation is quite different from that in the CRGT cycles, in which high conversion of methane, and therefore supplementary combustion are not essential, because the unconverted reactants are utilized as fuel.

The conceptual plant configurations proposed in this study are based on the above considerations, and they combine the CRGT concept with oxy-fuel combustion. Heat is extracted from the turbine exhaust for reforming with a medium methane conversion rate. An air separation unit is needed to produce oxygen as the combustion oxidizer. $\mathrm{CO}_{2}$ is separated by water condensation, and is subsequently compressed for liquefaction and storage.

\section{The reference power plant configuration}

Two power plant configurations have been investigated. They differ from each other mainly in the integration manner of turbine exhaust heat recovery with the reforming process and with the steam generation process.

Configuration I is our reference system shown in Fig. 1. It can be roughly divided into four sections: reforming process (2-3-4-5-6-7-8), power generation, exhaust heat recovery for steam generation (21-22-23-24-25), and $\mathrm{CO}_{2}$ compression (28-30).
In the reforming process section, the steam and natural gas mixture (2) (of 2:1 molar ratio to avoid solid carbon formation) is preheated up to about $600{ }^{\circ} \mathrm{C}$ (3) by heat recovery from the hot syngas generated in this reforming process, and enters the adiabatic reactor pre-reformer (PRE-REF), where the heavier hydrocarbons are reformed. Due to the endothermality of the process, the reforming gas temperature drops to about $480{ }^{\circ} \mathrm{C}$ (at 4) and is pre-heated again to $594^{\circ} \mathrm{C}$ to feed the reformer (REF). The reformer operates at about the combustion pressure (15.6 bar). It may adopt the conventional counterflow design with the reformer tubes filled with suitable catalyst. The cold-side fuel gases flow through this packed bed, the high-pressure gas turbine (HPT) exhaust (11-12) flowing on the shell side to provide the heat necessary for reforming. The minimal heat transfer temperature difference inside the reformer is chosen to be $30^{\circ} \mathrm{C}$, and the heat loss is not taken into consideration. Before feeding to the combustor, the syngas (6) heat is recuperated in heat exchangers (HEX)1 and 2 for preheating the reactants.

The combustion of the syngas (8) in the combustor is with oxygen, supplying $2 \%$ excess oxygen. The oxygen is assumed to be produced in a conventional cryogenic vapor compression air separation plant with the specific energy consumption of $812 \mathrm{~kJ} / \mathrm{kg} \mathrm{O}_{2}$ [21].

Power is generated by two gas turbines (HPT and lowpressure gas turbine (LPT)), and a high-pressure steam turbine (HPST). The power generation section can be regarded as a combination of: (1) a recuperated oxy-fuel gas turbine cycle with steam injection, and (2) a steam Rankine-type cycle. The recuperated gas turbine system provides heat (in 11-12 and 12-13) for the reforming process and for steam generation in the heat recovery

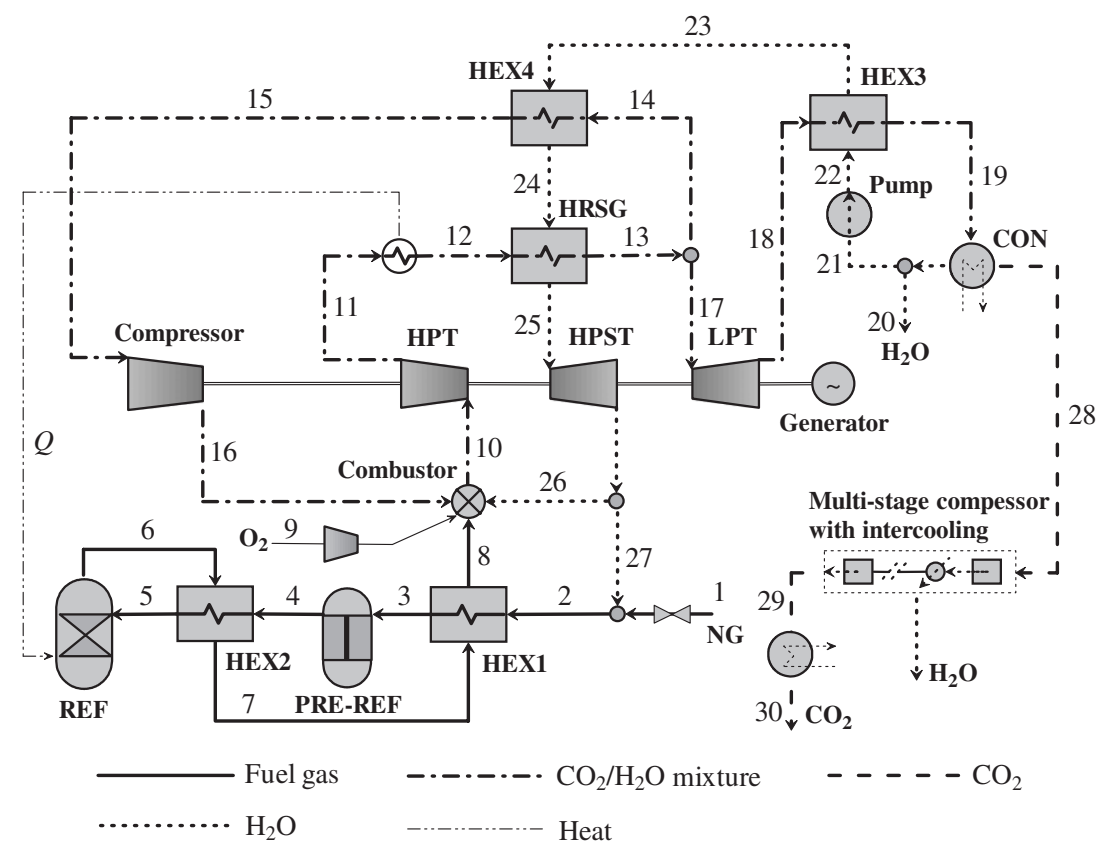

Fig. 1. Process flowsheet of Configuration I. 
steam generator (HRSG). The steam Rankine system recovers the exhaust heat from the gas turbine system and provides steam for both combustion injection (26) and steam reforming (27). The heat recovery section, including heat exchangers HEX3, HEX4 and HRSG, serves as the boiler for the Rankine-like cycle.

The HPT flue gas composition was calculated to be $\sim 87 \% \quad \mathrm{H}_{2} \mathrm{O}$ and $\sim 11 \% \mathrm{CO}_{2}$ by volume, and a small fraction of $\mathrm{O}_{2}, \mathrm{~N}_{2}$ and Ar. After transferring heat for steam generation in HRSG, it is split into two streams (streams 14 and 17), recycling stream 14 back to the compressor after cooling it (14-15) by preheating the Rankine cycle working fluid in HEX4 (23-24). Stream 17 is expanded further for power generation in LPT to a fairly low-pressure level ( 0.08 bar in this study), and the water contained is condensed and partly recycled as the Rankine cycle working fluid (21). Despite the overall high system pressure ratio, the pressure ratios of the gas turbines HPT and LPT are only $\sim 15$ and $\sim 12.5$, respectively, the same as those in standard air-based ones. The configuration of the power generation section is basically similar to the S-Graz cycle [21]. The arrangement of the higher pressure (higher heat capacity) but lower mass flow rate fluid on the Rankine cycle side of the heat recovery section, with the lower pressure (lower heat capacity) but higher mass flow rate fluid on the Brayton cycle side is intended for reduction of heat transfer irreversibilities in the heat exchangers.

The combustion-generated $\mathrm{CO}_{2}$ is separated and compressed to 110 bar (29) in a separate seven-stage compressor with intercooling for further disposition.

\section{Configuration modifications and calculation results}

The proposed systems have all been simulated with the ASPEN PLUS software [28], in which the component models are based on the energy balance and mass balance, with the default relative convergence error tolerance of $0.01 \%$. The RK-Soave thermodynamic model was selected for the thermal property calculations. The principal reactors (PRE-REF, REF) have been simulated by the Gibbs Reactor [2] available in the ASPEN PLUS model library, which determines the equilibrium conditions by minimizing Gibbs free energy (while not always accurate because it assumes complete equilibration, this is a simple model that can only be improved once the specific design of the reactors is completed). The main assumptions for simulations are summarized in Table 1, and some properties of feed streams are reported in Table 2. The system boundary is defined to include all units which contribute to the net system efficiency, so the process material streams are inflows of fuel (natural gas), and $\mathrm{O}_{2}$, outflows of pressurized $\mathrm{CO}_{2}$ and condensed $\mathrm{H}_{2} \mathrm{O}$, and cooling water (in- and out-flow). The energy streams include electricity output, and the power for $\mathrm{O}_{2}$ production. Other energy loss contributors (includes mechanical loss and generator loss) are taken into account by assuming a 3\% reduction of the gross power output.
Table 1

Main assumptions for the calculation

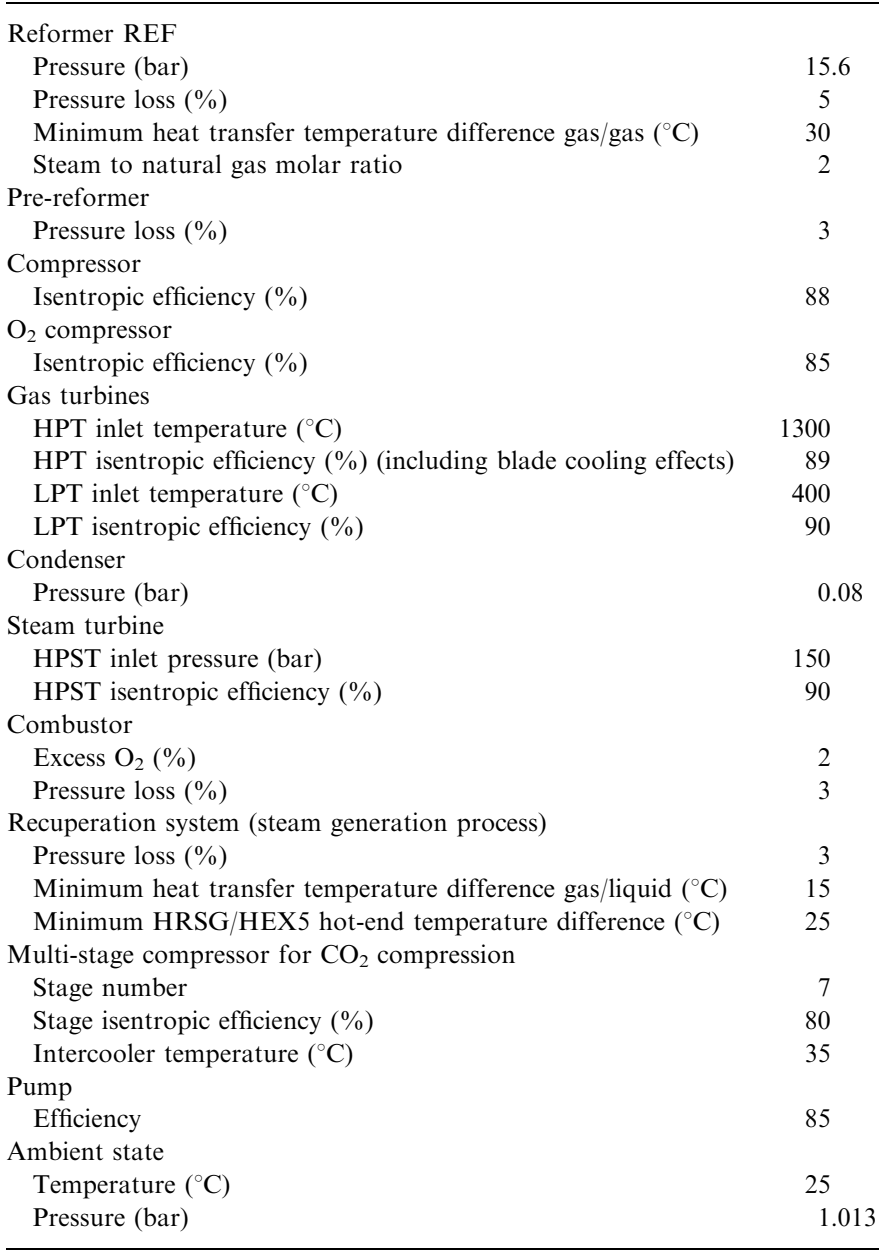

Table 2

Composition and some properties for feed streams

\begin{tabular}{lll}
\hline & Natural gas & Oxygen \\
\hline $\mathrm{CH}_{4}(\mathrm{~mol} \%)$ & 91.18 & \\
$\mathrm{C}_{2} \mathrm{H}_{6}(\mathrm{~mol} \%)$ & 4.41 & \\
$\mathrm{C}_{3} \mathrm{H}_{8}(\mathrm{~mol} \%)$ & 0.1 & \\
$\mathrm{~N}_{2}(\mathrm{~mol} \%)$ & 4.31 & 2 \\
$\mathrm{O}_{2}(\mathrm{~mol} \%)$ & & 95 \\
$\mathrm{Ar}(\mathrm{mol} \%)$ & & 3 \\
Temperature $\left({ }^{\circ} \mathrm{C}\right)$ & 25 & 25 \\
Pressure $($ bar) & 40 & 2.38 \\
Lower heating value $(\mathrm{kJ} / \mathrm{kg})$ & 46300 & - \\
Power consumption for $\mathrm{O}_{2}$ production $(\mathrm{kJ} / \mathrm{kg})$ & - & 812 \\
\hline
\end{tabular}

Steam is preferable for cooling the HPT blades, and can be accomplished with a small fraction of the steam extracted from HRSG [23]. Nevertheless, in the preliminary analysis in this paper, it is assumed that the HPT isentropic efficiency of $89 \%$ takes into account the blade cooling effects; compare to the value of $91 \%$ used in Ref. [15]. The reference system Configuration I was found to have a net plant energy efficiency of $50.8 \%$. A sensitivity analysis was preformed to investigate the influence of the 
HPT isentropic efficiency on the net plant efficiency. It was found that variation of the turbine isentropic efficiency from $88 \%$ to $91 \%$ changed the plant efficiency from $50.5 \%$ to $51.6 \%$, i.e., a $1 \%$-point increase of the turbine efficiency leads to about $0.36 \%$ point increase of the net plant efficiency. Another important parameter is the cycle condensation pressure or the LPT backpressure. Reduction of the LPT backpressure will lead to a higher power output and therefore to a higher plant efficiency. For example in Configuration I, when the LPT backpressure drops from 0.082 bar to 0.062 bar, the system efficiency increases from $50.8 \%$ to $51.4 \%$. Lower pressures were not considered because of the potential problem of air inleakage.

In Configuration I, the reformer and HRSG are placed in series on the turbine exhaust heat recovery line. The HPT exhausts at the temperature of $764{ }^{\circ} \mathrm{C}$. Since the minimum temperature difference is fixed at $30^{\circ} \mathrm{C}$ inside the reformer, the syngas temperature can at most reach $734{ }^{\circ} \mathrm{C}$ at the $\mathrm{REF}$ exit, and the syngas composition is considered to reach chemical equilibrium at the reformer exit. The reformer REF is composed of two sections, one adiabatic $\left(5-5^{\prime}\right.$ in Fig. 2a) with the reforming gas temperature drop of $62^{\circ} \mathrm{C}$, arranged with the placement of PRE-REF, which is also adiabatic with limited conversion rate and a temperature drop of $120^{\circ} \mathrm{C}$, to enable the attainment of the reforming process gas temperature profile shown in Fig. 2a. This makes it possible to cool the hot HPT exhaust to a lower temperature value, and consequently to maximize the exhaust heat recovery for reforming and to maximize the final reforming temperature.

Fig. $2 \mathrm{~b}$ is the $T-Q$ diagram of the heat transfer process in the water preheating and steam generation process. The minimal temperature difference for the gas/liquid heat transfer in HEX3 and HEX4 is fixed to be $15^{\circ} \mathrm{C}$. After transferring heat to the reformer, the turbine exhaust is cooled to $651{ }^{\circ} \mathrm{C}$, which is used to produce steam in the HRSG at $620^{\circ} \mathrm{C}$. This value is comparable with the current technology level of steam turbine power plants.

Although using steam as the working fluid, the HPST works more like a gas turbine, with the working fluid being always in the gaseous phase and with a pressure ratio of only 9. Higher HPST inlet temperatures would have, however, favored the overall plant performance. To increase this temperature, the reference system configuration has been slightly modified to form the Configuration II shown in Fig. 3, in which the reformer and HEX5 (superheater) are in parallel for the heat recovery. A splitter is introduced, which divides the HPT exhaust into two streams, 11a $(68 \%$, determined by the reformer heat demand) and $11 \mathrm{~b}(32 \%)$. Stream 11a provides heat for the reforming process; while stream $11 \mathrm{~b}$ superheats the stream (25) to a higher temperature of $739^{\circ} \mathrm{C}$ determined by the HEX5 minimal hot end temperature difference. While this temperature is somewhat higher than used in current steam turbines, it is expected that turbines operating at or above this temperature level will become commercially available in the near future [12,13]. The parallel connection enables both the reformer and HEX5 to work at the highest temperature levels. As a result, the HPST power output increased by $13.4 \%$, and its exhaust temperature increases too, leading to the increase of the combustor inlet syngas temperature. The PRE-REF and REF are operating under the same conditions (temperature, pressure and steam-natural gas molar ratio) as that in Configuration I.

The $T-Q$ diagrams of the reforming process and the steam generation and superheating process are shown in Figs. $4 \mathrm{a}$ and $\mathrm{b}$, respectively. The $\Delta T_{\min }$ in $\mathrm{HEX} 4$ is $15^{\circ} \mathrm{C}$. As seen in Fig. 4a, the arrangement of the heat exchange in the reforming section and the syngas parameters are the same as in the Configuration I, and the turbine exhaust has a

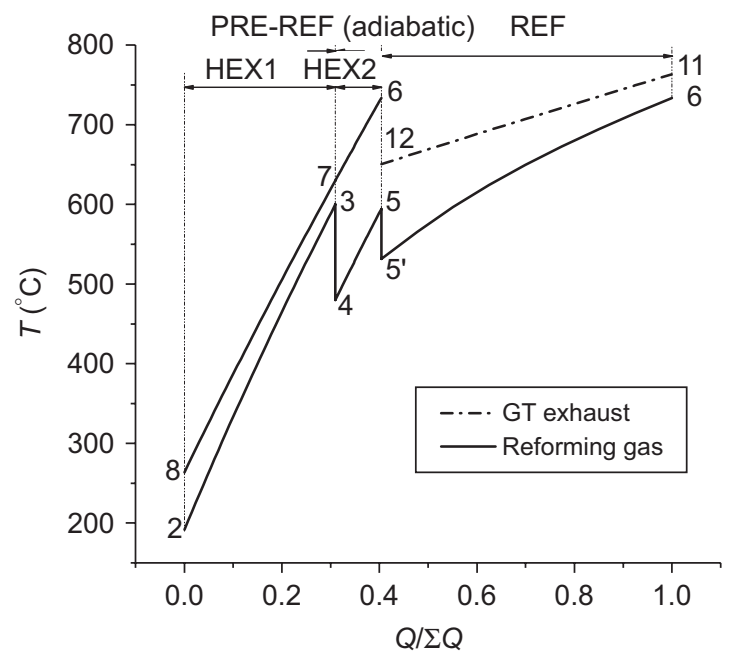

b

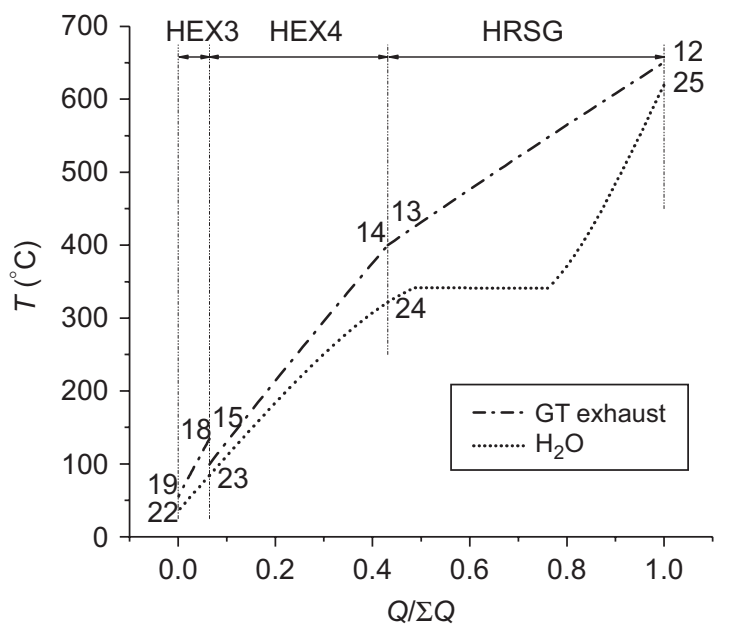

Fig. 2. (a) The $T-Q$ diagram in the reforming process of Configuration I. (b) The $T-Q$ diagram in the steam generation process of Configuration I. 
a bigger temperature drop in the reforming process due to the stream splitting. The thermal matches between the turbine exhaust with syngas $\left(5^{\prime}-6\right)$ in Fig. (4a), and with steam generation process (22-23-24-25-25a) in Fig. (4b) are both improved significantly and thus the heat transferrelated irreversibility decreases, as will be addressed in the following paragraphs. Naturally, this closer thermal match requires a larger heat transfer surface area or better heat exchangers in terms of design and materials, and possibly

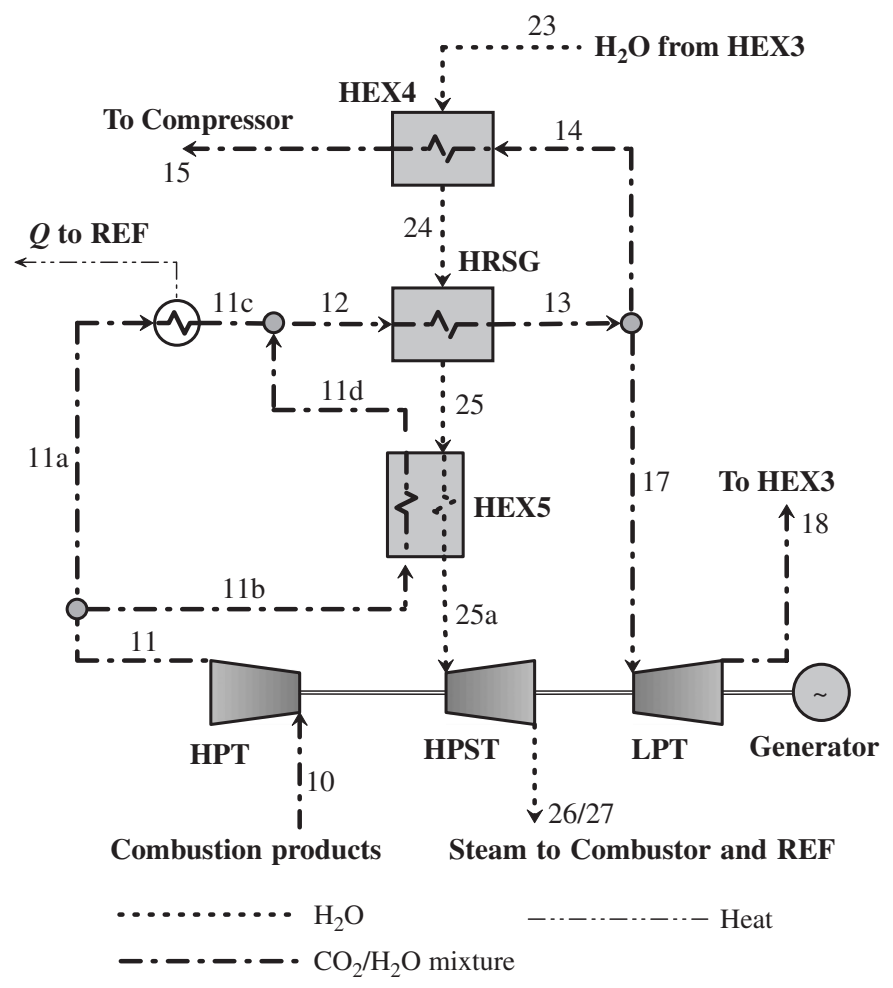

Fig. 3. Variations introduced in Configuration II (relative to Configuration I). higher pumping power for the fluids if higher heat transfer coefficients are sought for that purpose. This is the typical compromise between cost and performance.

Some stream state parameters for the two configurations are presented in Tables 3 and 4, respectively.

It is of interest to compare the proposed systems to ones that were proposed and investigated in the past, such as the various oxy-fuel-based cycles with $\mathrm{CO}_{2} / \mathrm{H}_{2} \mathrm{O}$ recycling, including the Water cycle and the Graz cycle that use water as the main working fluid. The Water cycle with steam recycle is based on high-pressure, high-temperature steam cycle technology developed and tested by CES $[12,13]$. In the Graz cycle presented in [14], the stream split is introduced after the expansion in the LPT, $\mathrm{CO}_{2}$ and water are separated by water condensation, and then only $\mathrm{CO}_{2}$ is recycled back to the combustor. In a most recent version, the S-Graz cycle, the stream split is introduced before the expansion in LPT, in this way the recycled stream is a mixture of $\mathrm{CO}_{2}$ and vapor. An analysis [21] concluded that the S-Graz cycle has higher plant efficiency comparing with the Water cycle.

It is relatively easy to compare the cycles we proposed here to the Graz cycle, since elimination of the reformingrelated components in the reference system Configuration I changes it to a Graz-like cycle (S-Graz version). We then compare its performance to a Graz cycle modified somewhat in its configuration and operation parameters to allow equitable comparison. That comparison Graz cycle flowsheet diagram is shown in Fig. 5. It differs from the one analyzed in [21] in that it has only one compressor (instead of two compressors with intercooling used in [21]), and in that a heat exchanger (HEX3 in Fig. 5) is added to recover the LPT exhaust heat. It is simulated using the same assumptions contained in Table 1. The recycled flue gas (stream 14 in Fig. 5) fraction is 50.5\% in this calculation, determined by the heat demand for water a

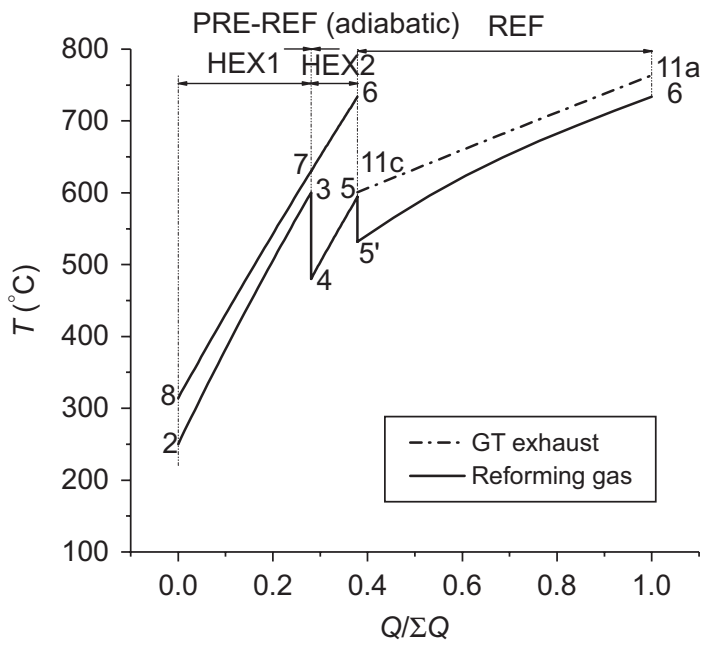

b

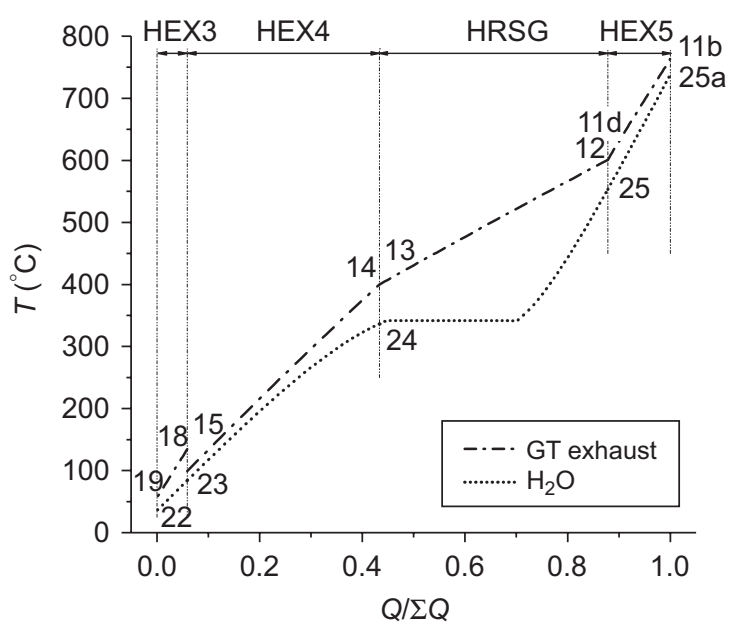

Fig. 4. (a) The $T-Q$ diagram in the reforming process of Configuration II. (b) The $T-Q$ diagram in the steam generation and superheating process of Configuration II. 
Table 3

Mainstream states of Configuration I (the state point numbers refer to Fig. 1)

\begin{tabular}{|c|c|c|c|c|c|c|c|c|c|c|c|c|}
\hline \multirow[t]{2}{*}{ No. } & \multirow[t]{2}{*}{$T\left({ }^{\circ} \mathrm{C}\right)$} & \multirow[t]{2}{*}{$P$ (bar) } & \multirow[t]{2}{*}{$m(\mathrm{~kg} / \mathrm{s})$} & \multicolumn{9}{|c|}{ Molar composition (\%) } \\
\hline & & & & $\mathrm{CH}_{4}$ & $\mathrm{C}_{2} \mathrm{H}_{6}$ & $\mathrm{H}_{2}$ & $\mathrm{CO}$ & $\mathrm{CO}_{2}$ & $\mathrm{H}_{2} \mathrm{O}$ & $\mathrm{O}_{2}$ & $\mathrm{~N}_{2}$ & $\mathrm{Ar}$ \\
\hline \multicolumn{13}{|c|}{ Reforming section } \\
\hline 2 & 191.8 & 16.95 & 53.24 & 30.4 & 1.5 & & & & 66.7 & & 1.4 & \\
\hline 3 & 600 & 16.8 & 53.24 & 30.4 & 1.5 & & & & 66.7 & & 1.4 & \\
\hline 4 & 480 & 16.35 & 53.24 & 27.7 & & 12.1 & 0.1 & 3.3 & 55.4 & & 1.3 & \\
\hline 5 & 594.2 & 16.2 & 53.24 & 27.7 & & 12.1 & 0.1 & 3.3 & 55.4 & & 1.3 & \\
\hline 6 & 733.5 & 15.6 & 53.24 & 12.4 & & 43 & 6.3 & 6.3 & 31 & & 1.1 & \\
\hline 8 & 263.9 & 15.45 & 53.24 & 12.4 & & 43 & 6.3 & 6.3 & 31 & & 1.1 & \\
\hline \multicolumn{13}{|c|}{ Power generation section } \\
\hline 10 & 1300 & 15 & 470.04 & & & & & 11 & 86.9 & 0.4 & 0.9 & 0.7 \\
\hline 11 & 763.4 & 1.05 & 470.04 & & & & & 11 & 86.9 & 0.4 & 0.9 & 0.7 \\
\hline 12 & 650.7 & 1.04 & 470.04 & & & & & 11 & 86.9 & 0.4 & 0.9 & 0.7 \\
\hline 17 & 400 & 1.03 & 193.4 & & & & & 11 & 86.9 & 0.4 & 0.9 & 0.7 \\
\hline 18 & 134.3 & 0.082 & 193.4 & & & & & 11 & 86.9 & 0.4 & 0.9 & 0.7 \\
\hline 25 & 620 & 150 & 107.73 & & & & & & 100 & & & \\
\hline 27 & 291.3 & 16.95 & 36.03 & & & & & & 100 & & & \\
\hline \multicolumn{13}{|c|}{$\mathrm{CO}_{2}$ compression section } \\
\hline 28 & 38 & 0.08 & 74.29 & & & & & 39.8 & 52.7 & 1.6 & 3.4 & 2.5 \\
\hline 29 & 35 & 110 & 50.4 & & & & & 84 & 0.2 & 3.3 & 7.2 & 5.3 \\
\hline
\end{tabular}

Table 4

Some variations of the stream states of Configuration II (the state point numbers refer to Figs. 1 and 3 )

\begin{tabular}{|c|c|c|c|c|c|c|c|c|c|c|c|c|}
\hline \multirow[t]{2}{*}{ No. } & \multirow[t]{2}{*}{$T\left({ }^{\circ} \mathrm{C}\right)$} & \multirow[t]{2}{*}{$P$ (bar) } & \multirow[t]{2}{*}{$m(\mathrm{~kg} / \mathrm{s})$} & \multicolumn{9}{|c|}{ Molar composition (\%) } \\
\hline & & & & $\mathrm{CH}_{4}$ & $\mathrm{C}_{2} \mathrm{H}_{6}$ & $\mathrm{H}_{2}$ & $\mathrm{CO}$ & $\mathrm{CO}_{2}$ & $\mathrm{H}_{2} \mathrm{O}$ & $\mathrm{O}_{2}$ & $\mathrm{~N}_{2}$ & $\mathrm{Ar}$ \\
\hline \multicolumn{13}{|c|}{ Reforming section } \\
\hline 2 & 249.9 & 16.95 & 53.24 & 30.4 & 1.5 & & & & 66.7 & & 1.4 & \\
\hline 8 & 314.2 & 15.45 & 53.24 & 12.4 & & 43 & 6.3 & 6.3 & 31 & & 1.1 & \\
\hline \multicolumn{13}{|c|}{ Power generation section } \\
\hline 10 & 1300 & 15 & 484.08 & & & & & 11.3 & 86.6 & 0.4 & 1.0 & 0.7 \\
\hline $11 \mathrm{a}$ & 763.6 & 1.05 & 329.18 & & & & & 11.3 & 86.6 & 0.4 & 1.0 & 0.7 \\
\hline $11 \mathrm{c}$ & 600.8 & 1.04 & 329.18 & & & & & 11.3 & 86.6 & 0.4 & 1.0 & 0.7 \\
\hline $11 d$ & 600.9 & 1.04 & 154.91 & & & & & 11.3 & 86.6 & 0.4 & 1.0 & 0.7 \\
\hline 25 & 553.2 & 151 & 103.68 & & & & & & 100 & & & \\
\hline $25 \mathrm{a}$ & 738.7 & 150 & 103.68 & & & & & & 100 & & & \\
\hline 27 & 384.8 & 16.95 & 36.03 & & & & & & 100 & & & \\
\hline
\end{tabular}

preheating. By retrieving heat from the gas turbines exhausts, steam at the temperature of $620^{\circ} \mathrm{C}$ (the same as that in Configuration I) is produced for power generation in HPST, and then injected back into the combustor.

The $T-Q$ diagram of the recuperation process for steam generation in this comparison Graz cycle is shown in Fig. 6. As seen, a much higher average heat transfer temperature difference results, which would causes a big heat transfer-related exergy destruction in the Graz comparative cycle.

\section{Overall performance comparison and discussion}

The overall performance of the three system configurations is summarized in Table 5. The calculations use the same natural gas input $(3600 \mathrm{kmol} / \mathrm{h})$ and the same steam/ natural gas molar ratio (2:1) entering the reforming process. Therefore the plant energy input, the $\mathrm{O}_{2}$ consumed $(68.5 \mathrm{~kg} / \mathrm{s})$, and the related energy consumption (55.6 and 15.3 MW) for $\mathrm{O}_{2}$ production and compression, are all the same.

The analysis shows that Configuration I has a net power output of $404.8 \mathrm{MW}$, with an energy efficiency of $50.8 \%$. Most of the power (68.7\% natural gas LHV (NG LHV)) is generated by the HPT. The compressor consumes more power than that produced by the LPT and HPST. The Configuration II with the parallel connection of REF and HEX5 has higher power output than the reference system Configuration I, and its energy efficiency is higher by 1.3 percentage points. The comparison Graz cycle 


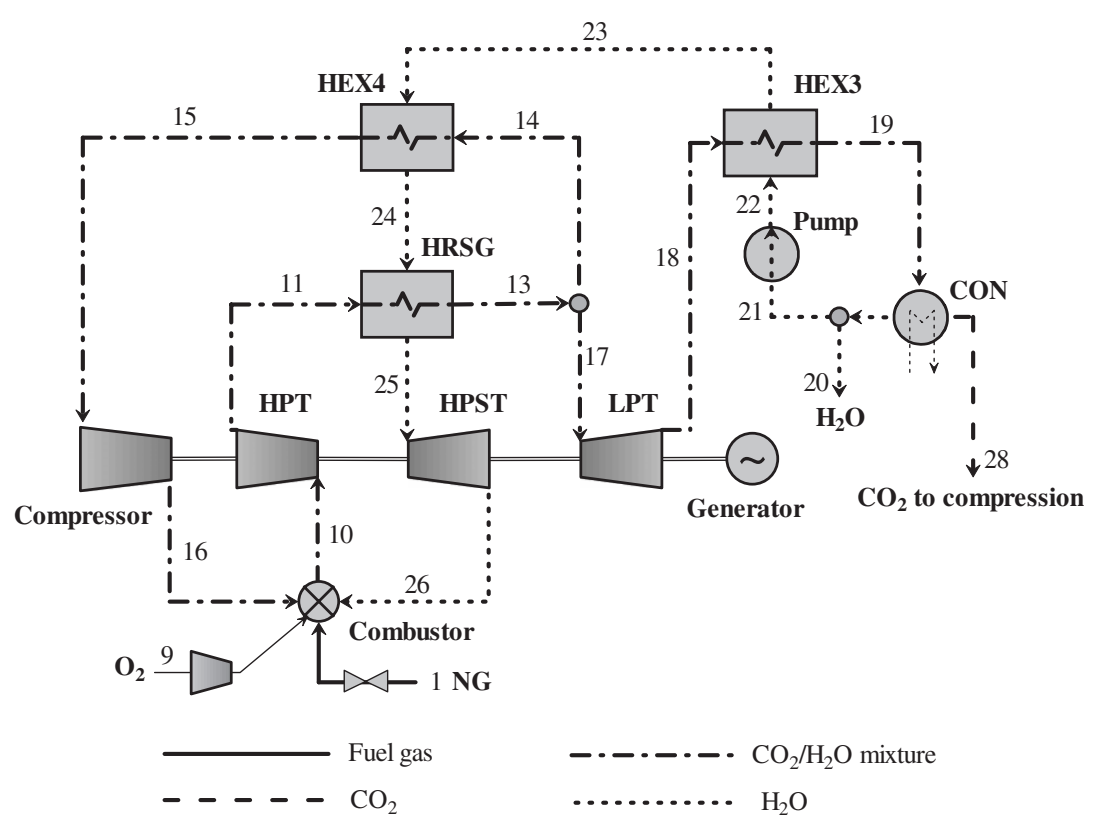

Fig. 5. Process flowsheet of the comparison S-Graz cycle.

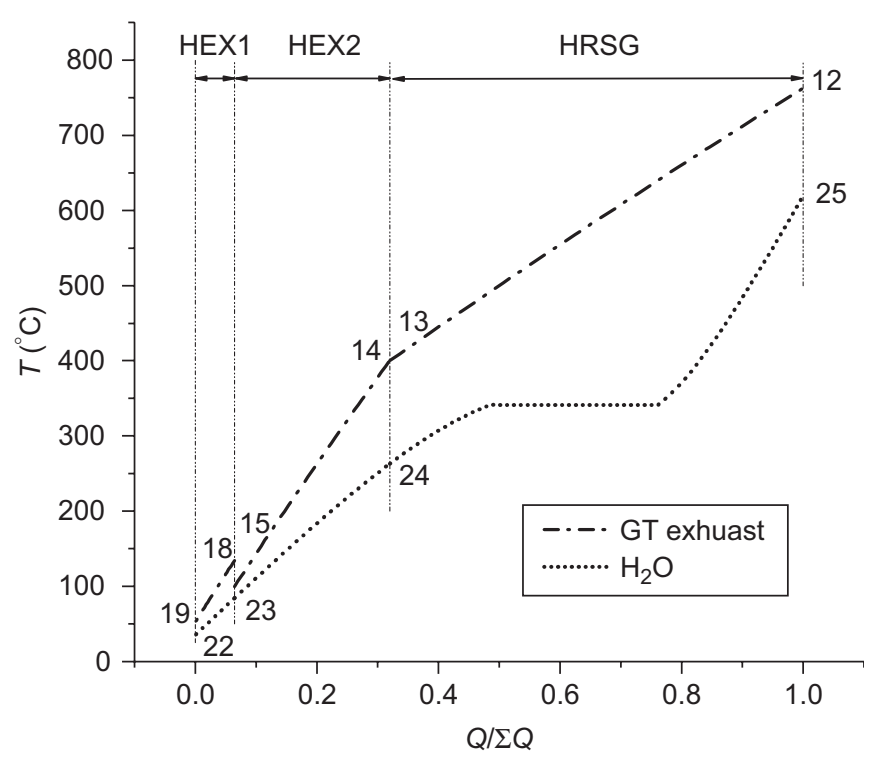

Fig. 6. The $T-Q$ diagram in the steam generation process of the S-Graz cycle.

has the lowest power output, and an energy efficiency of $48.6 \%$.

The Configurations I and II have the same methane conversion rate $(45.4 \%)$ because of the same reformer exit temperature.

Part of the HPT flue gas is recycled back to the compressor, its sensible heat is mainly utilized to preheat water (in HEX4); therefore the recycled fraction is determined by the heat demand of the water side, and by the minimal heat transfer temperature difference. Since the recycled flue gas used for heat recovery is then compressed and fed back to the combustor, its fraction also has influence on the compressor power consumption and on both HPT and LPT power outputs.

In the reference Configuration I, the recycled stream fraction is $58.9 \%$. In Configurations II, steam can be produced at a higher temperature $\left(739^{\circ} \mathrm{C}\right)$, thus the HPST produces more power $(1.08 \%$ NG LHV) compared with that in the reference system Configuration I, requiring a larger HPT flue gas recycle fraction $(60.9 \%)$ for more heat extraction. The higher recycling demand also leads to the increase of the HPT working fluid mass flow rate. Higher power generation in the HPT, as well as in the HPST, contribute to the overall power output and energy efficiency increases in the Configuration II.

In the Graz cycle, the steam turbine power output is higher than that in the configurations with steam reforming, because all the turbine exhaust heat is utilized for producing more steam. Less turbine flue gas recycling $(50.5 \%)$ is therefore required for preheating the water, leading to a drop in the working fluid flow rate in both the compressor and HPT. As a result, the compressor power consumption and HPT power output drop by $5.5 \%$ and $9.1 \%$ NG LHV, respectively, as compared with the reference Configuration I. In the Graz cycle, the $0.82 \%$ NG LHV increase of the HPST power output, and the decrease of the compressor power consumption cannot compensate for the HPT output decrease and its energy efficiency consequently decreases by $2.2 \%$ points.

The $\mathrm{O}_{2}$ production by the ASU consumes $7 \%$ of the total NG LHV, and its compression consumes an additional $1.9 \%$. The $\mathrm{CO}_{2}$ compression work consumes $4.6 \%$ of the NG LHV. The generator and other auxiliary losses are assumed to be $3 \%$ of the system gross power output, consuming about $1.5-1.6 \%$ of the NG LHV input. 
Table 5

Breakdown of power generation and consumption in $\%$ of fuel LHV, and total heat exchanger area

\begin{tabular}{|c|c|c|c|c|c|c|}
\hline & \multicolumn{2}{|c|}{ Configuration I } & \multicolumn{2}{|c|}{ Configuration II } & \multicolumn{2}{|c|}{ Graz cycle } \\
\hline & MW & $\%$ & MW & $\%$ & MW & $\%$ \\
\hline HPT turbine & 546.99 & 68.66 & 561.27 & 70.46 & 474.32 & 59.54 \\
\hline LPT turbine & 88.63 & 11.13 & 86.48 & 10.86 & 92.49 & 11.61 \\
\hline HPST turbine & 64.13 & 8.050 & 72.7 & 9.126 & 70.68 & 8.873 \\
\hline Compressor & 172.80 & 21.69 & 183.33 & 23.01 & 128.63 & 16.15 \\
\hline Water pump & 1.99 & 0.250 & 1.91 & 0.240 & 2.12 & 0.266 \\
\hline $\mathrm{CO}_{2}$ compression & 36.68 & 4.605 & 36.68 & 4.605 & 36.68 & 4.605 \\
\hline $\mathrm{O}_{2}$ production & 55.59 & 6.978 & 55.59 & 6.978 & 55.59 & 6.978 \\
\hline $\mathrm{O}_{2}$ compression & 15.31 & 1.922 & 15.31 & 1.922 & 15.31 & 1.922 \\
\hline Generator and mechanical loss & 12.52 & 1.572 & 12.83 & 1.611 & 11.97 & 1.503 \\
\hline Net power output & 404.84 & 50.82 & 414.78 & 52.07 & 387.17 & 48.60 \\
\hline Natural gas LHV input & 796.61 & 100.0 & 796.61 & 100.0 & 796.61 & 100.0 \\
\hline Total heat exchanger area $\left(\mathrm{m}^{2}\right)$ & \multicolumn{2}{|c|}{$223,588^{\mathrm{a}}$} & \multicolumn{2}{|c|}{$232,104^{\mathrm{a}}$} & \multicolumn{2}{|c|}{218,860} \\
\hline
\end{tabular}

${ }^{\text {a }}$ Excluding the reformer.

Table 6

Exergy analysis results of the three systems

\begin{tabular}{|c|c|c|c|c|c|c|}
\hline & \multicolumn{2}{|c|}{$\begin{array}{l}\text { Configuration } \\
\text { I }\end{array}$} & \multicolumn{2}{|c|}{$\begin{array}{l}\text { Configuration } \\
\text { II }\end{array}$} & \multicolumn{2}{|c|}{ Graz cycle } \\
\hline & MW & $\%$ & MW & $\%$ & MW & $\%$ \\
\hline \multicolumn{7}{|l|}{ Exergy input } \\
\hline Natural gas exergy & 843.8 & 100 & 843.8 & 100 & 843.8 & 100 \\
\hline $\mathrm{O}_{2}$ stream exergy & 11.25 & 1.33 & 11.25 & 1.33 & 11.25 & 1.33 \\
\hline \multicolumn{7}{|l|}{ Exergy output } \\
\hline Net power output & 404.84 & 47.98 & 414.78 & 49.16 & 387.17 & 45.88 \\
\hline $\mathrm{CO}_{2}$ stream exergy & 41.48 & 4.92 & 41.48 & 4.92 & 41.48 & 4.92 \\
\hline \multicolumn{7}{|l|}{ Exergy change } \\
\hline Reforming process & 17.29 & 2.05 & 17.22 & 2.04 & - & - \\
\hline Combustion & 223.77 & 26.52 & 216.41 & 25.65 & 244.64 & 28.99 \\
\hline Steam generation process & 42.44 & 5.03 & 38.97 & 4.62 & 61.29 & 7.26 \\
\hline Turbines and compressors & 41.57 & 4.93 & 42.28 & 5.01 & 37.42 & 4.43 \\
\hline $\mathrm{CO}_{2}$ compression & 15.50 & 1.84 & 15.49 & 1.84 & 15.49 & 1.84 \\
\hline $\mathrm{O}_{2}$ production & 55.59 & 6.59 & 55.59 & 6.59 & 55.59 & 6.59 \\
\hline Generator and Mech. loss & 12.52 & 1.48 & 12.83 & 1.52 & 11.97 & 1.42 \\
\hline
\end{tabular}

For guiding system performance improvement, the exergy changes inside the systems are decomposed. The component exergy change is defined as the change in exergy between the entry state and the exhaust state of each process. The results are presented in Table 6 and Fig. 7. The combustion-associated exergy change is, as usual, the biggest item [29,30]. That change is evidently lower (by $2.5 \%$ and $3.3 \%$ points, respectively) in the configurations with reforming than in the comparison Graz cycle, since reforming elevates the fuel heating value. These configurations, however, do not show much superiority when the sum of the exergy changes in both the reforming and combustion processes are taken into account, because of the relatively lower reforming temperatures and conversion rates. Supplementary combustion or ATR

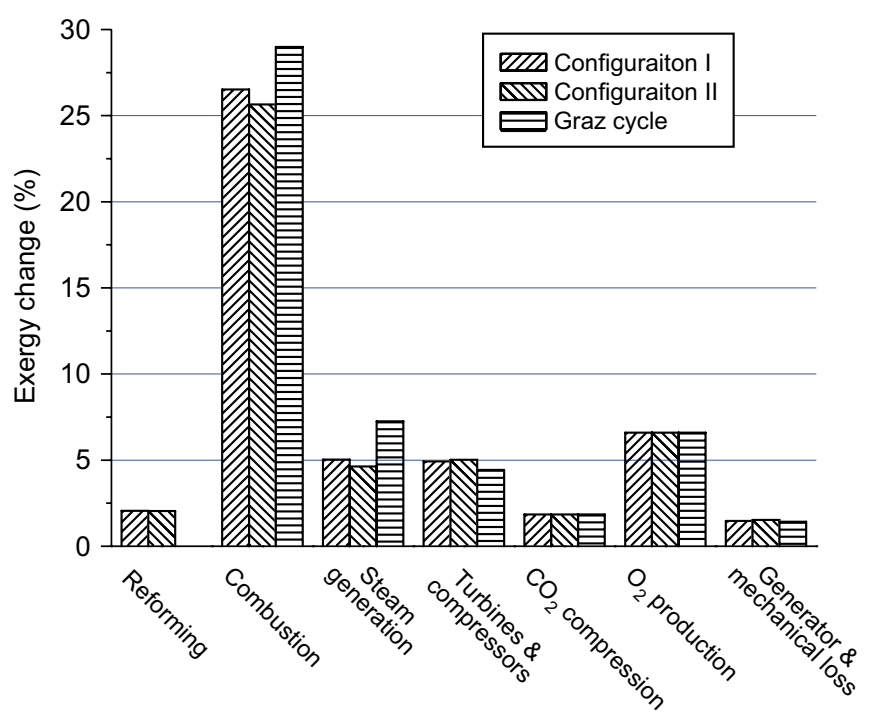

Fig. 7. The exergy changes in the main processes of the three systems.

are alternatives for elevating the reforming temperature and the conversion rate, with the expense of burning some natural gas in the supplementary combustor or reformer. Supplementary combustion usually is considered to have a negative effect on the overall efficiency because the supplementary energy is only utilized at the lower temperature level. Some cycle proposals with ATR are reported to be superior to their steam reforming cousins [1,22-24]. Another possible way to raise the conversion rate is to reduce the reformer operating pressure, but a fuel compressor is then needed to raise the syngas pressure to the combustion level. The influence of all these improvement proposals needs further investigation.

Comparing with the Graz cycle, another significant improvement is found in the recuperation process of steam generation and superheating. The better thermal match in 
the Configurations I and II of our system helps reduce the heat transfer irreversibilities by about $2.4 \%$ points on average. Configuration II with parallel connection also show superiority to the reference Configuration $I$ in the combustion and steam generation processes, because of the better heat exchanger arrangement. The Graz cycle has a slightly lower exergy loss in the turbines and compressor because of its lower power output.

The better thermal match, or lower average logarithmic mean temperature difference (LMTD), are obviously obtained at the expense of additional required heat exchanger surface area, or better heat exchangers, which may lead to a higher equipment cost, and it is therefore important to evaluate the heat exchanger requirements for the different system configurations. Precise evaluation would require decisions on the heat exchanger design, so we have used here typical overall heat transfer coefficients from [31], that are based on the type of fluids, their phase, pressure and the $Q / L M T D$ values. Condenser (CON), HRSG and HEX5 were considered to be shell-and-tube heat exchangers, and the others of the plate-fin type. Apart from the reformers needed for the novel Configurations I and II systems, this integration is achieved with only a $6 \%$ increase in heat exchanger area relative to the comparison Graz cycle. It is noteworthy that $\mathrm{CON}$ requires more than $79 \%$ of the total heat exchanger area in all three considered systems.

The energy consumption and therefore the exergy change for $\mathrm{CO}_{2}$ compression and $\mathrm{O}_{2}$ production and compression are the same for all the configurations, because of the same natural gas feed rate and combustion temperature. The $\mathrm{CO}_{2}$ compression is assumed to be accomplished with a seven-stage compressor with intercooling, its exergy consumption accounts for nearly $1.84 \%$ of the total exergy input, and the power consumption for $\mathrm{O}_{2}$ production accounts for $6.6 \%$ of the total exergy input, and its compression adds $0.16 \%$ to the item of turbines and compressors exergy change. This is normal for the oxy-fuel cycle when compared with other technologies for $\mathrm{CO}_{2}$ removal: the large energy consumption is shifted from the $\mathrm{CO}_{2}$ capture process to the $\mathrm{O}_{2}$ production process, which, after the combustion exergy loss takes the second place. Thus one possible improvement to the system configuration would be the integration of the system exothermic process with the air separation process, so that the coldness from the latter process could be used as the system heat sink or for $\mathrm{CO}_{2}$ separation.

As to the $\mathrm{CO}_{2}$ emission, the systems are considered to have a capture level of $\sim 100 \%$; however, a trace amount of $\mathrm{CO}_{2}$ will in any case be dissolved in the water. The captured high-pressure $\mathrm{CO}_{2}$ stream can be regarded as an exergy-valuable product of the system, owning $4.9 \%$ of the natural gas input exergy. With that consideration, the total exergy efficiency would be $52.9 \%$ for Configuration I, instead of $48 \%$ when based on the produced electricity only. The $\mathrm{CO}_{2}$ stream has a mass flow rate of $50.4 \mathrm{~kg} / \mathrm{s}$, and is a mixture of $84 \% \mathrm{CO}_{2}, 0.2 \% \mathrm{H}_{2} \mathrm{O}, 3.3 \% \mathrm{O}_{2}, 7.2 \% \mathrm{~N}_{2}$ and $5.3 \%$ Ar by volume. The presence of the noncondensable gases is mainly due to the oxygen and natural gas impurity, and the excess oxygen rate for complete combustion. Further purification might be required to remove some components prior to transportation and storage. According to [21], purifying the $\mathrm{CO}_{2}$ would incur a power cycle efficiency reduction up to $0.4 \%$ points, and would add to the overall cost. Davison [32] mentioned an oxy-fuel NGCC plant in which the flue gas with a $\mathrm{CO}_{2}$ concentration of $88 \mathrm{~mol} \%$ dry basis is compressed and the $\mathrm{CO}_{2}$ concentration is increased to $96 \mathrm{~mol} \%$ by a cryogenic unit for removal of inert gases that is integrated with the compression unit. In this paper, further purification and its effect was not taken into consideration: the mixture is compressed to $110 \mathrm{bar}$, and the calculation indicates that the pressurized mixture can be liquefied at a near-ambient temperature of $16^{\circ} \mathrm{C}$.

It is noteworthy that the novel system components are mainly based on commercially proven technology, except for the high-temperature steam turbine and the oxy-fuel combustor. The advanced high-temperature, high-pressure gas generator and steam turbine have been tested and demonstrated by CES: Pronske et al. [33] summarized the development of oxy-fuel combustor and turbine technology by CES and Siemens Power Generation for a 300-600 MW coal syngas plant with zero emission. A review about the oxy-fuel combustion was also given in [34] but focused on coal-fired power plants; experiments need to be done on burning natural gas as the fuel because of the different $\mathrm{CO}_{2} / \mathrm{O}_{2}$ atmosphere and different reactant compositions.

\section{Concluding remarks}

Two novel system configurations (Configurations I and II) that integrate natural gas reforming technology with an oxy-fuel semi-closed power cycle have been proposed for $\mathrm{CO}_{2}$ removal in a natural gas-fired power generation system. Water is used as the main working fluid, and the turbine exhaust is mainly a mixture of $\mathrm{H}_{2} \mathrm{O}(\sim 87 \%)$ and $\mathrm{CO}_{2}(\sim 11 \%$ by volume), which are subsequently separated from each other.

Their main features are summarized below, including those features common to oxy-fuel cycles (such as the Graz cycle), as well as some additional new merits:

- Internal combustion is used, which allows a very high average temperature in the cycle heat addition process.

- The $\mathrm{H}_{2} \mathrm{O} / \mathrm{CO}_{2}$ turbine working fluid can expand to a very low back pressure $(<0.1$ bar), which is near that employed in conventional steam turbines, and can thus produce more net power.

- The combustor is fed with both recycled flue gas and steam, but only the recycled flue gas needs to be compressed, and the injected water vapor is condensed and thus only needs very little pump work for its pressure elevation. 
- No high energy consumption devices are needed for the $\mathrm{CO}_{2}$ capture, but an air separation unit is required for supplying the combustion oxygen, consuming about $7 \%$ of the total system energy input.

- Steam reforming is employed for the turbine exhaust heat recovery, a method superior to the conventional thermal recuperation, and was proven to reduce the combustion exergy change.

- The reforming process is based on the available turbine exhaust heat recovery, with medium conversion rate. Compared with the pre-combustion decarbonization strategy, it eliminates the need for the syngas shift process because all of the syngas is used as fuel.

- Particular attention has been paid to the integration of the turbine exhaust heat recovery with both the reforming and steam generation processes, to reduce the heat transfer-related exergy change. The turbine exhaust heat is largely recuperated internally, and heat released to the environment is at very low-temperature level. Apart from the reformers needed for the novel Configrations I and II systems, this integration is achieved with only a $6 \%$ increase in heat exchanger area relative to the comparison Graz cycle.

- $\sim 100 \% \mathrm{CO}_{2}$ capture can be obtained.

Compared with the Graz cycle, it was found that the Configuration II system has the highest energy efficiency, of $52.1 \%$, followed by the Configuration I $(50.8 \%)$, both higher than that of the Graz cycle $(48.6 \%)$. The improvement is attributed primarily to a decrease of the exergy change in the combustion and steam generation processes that these novel systems offer. Parametric sensitivity analyses and optimization are needed for further performance improvement.

The proposed configurations with reforming require additional equipment components, mainly the REF and PRE-REF. This will add to the overall plant cost. The components are mainly based on commercially proven technology, except for the high-temperature steam turbine and the oxy-fuel combustor. Literature shows that the advanced high-temperature, high-pressure gas generator and steam turbine have been tested and demonstrated. Experiments need to be done on burning natural gas as the fuel because of the different $\mathrm{CO}_{2} / \mathrm{O}_{2}$ atmosphere and different reactant compositions.

\section{Acknowledgment}

The first author gratefully acknowledges the support of the Chinese Natural Science Foundation Project (No. 50520140517).

\section{References}

[1] Lozza G, Chiesa P. Natural gas decarbonization to reduce $\mathrm{CO}_{2}$ emission from combined cycles-Part I: partial oxidation. ASME J Eng Gas Turbines Power 2002;124:82-8.
[2] Corradetti A, Desideri U. Analysis of gas-steam combined cycles with natural gas reforming and $\mathrm{CO}_{2}$ capture. ASME J Eng Gas Turbines Power 2005; 127:545-52.

[3] Chiesa P, Consonni S. Natural gas fired combined cycles with low $\mathrm{CO}_{2}$ emissions. ASME J Eng Gas Turbines Power 2000;122: 429-36.

[4] Desideri U, Paolucci A. Performance modeling of a carbon dioxide removal system for power plants. Energy Convers Manage 1999;40:1899-915.

[5] Mathieu P, Nihart R. Zero-emission MATIANT cycle. J Eng Gas Turbines Power 1999;121:116-20.

[6] Mathieu P, Nihart R. Sensitivity analysis of the MATIANT cycle. Energy Convers Manage 1999;40:1687-700.

[7] Yantovski EI, Zvagolsky KN, Gavrilenko VA. The COOPERATEdemo power cycle. Energy Convers Manage 1996;37(6-8):861-4.

[8] Yantovski EI. Stack downward zero emission fuel-fired power plants concept. Energy Convers Manage 1996;37:867-77.

[9] Staicovici MD. Further research zero $\mathrm{CO}_{2}$ emission power production: the "COOLENERG" process. Energy 2002;27:831-44.

[10] Zhang N, Lior N. A novel near-zero $\mathrm{CO}_{2}$ emission thermal cycle with LNG cryogenic exergy utilization. Energy 2006;31:1666-79.

[11] Zhang N, Lior N. Proposal and analysis of a novel zero $\mathrm{CO}_{2}$ emission cycle with liquid natural gas cryogenic exergy utilization. J Eng Gas Turbine Power 2006;128:81-91.

[12] Anderson R, Brandt H, Doyle S, Pronske K, Viteri F. Power generation with $100 \%$ carbon capture and sequestration. In: Second annual conference on carbon sequestration. Alexandria, VA, 2003.

[13] Marin O, Bourhis Y, Perrin N, Zanno PD, Viteri F, Anderson R. High efficiency, zero emission power generation based on a hightemperature steam cycle. In: 28th International technical conference on coal utilization \& fuel systems. Clearwater, FL, USA, 2003.

[14] Jericha H, Gottlich E, Sanz W, Heitmeir F. Design optimization of the Graz cycle prototype plant. ASME J Eng Gas Turbines Power 2004; 126:733-40.

[15] Martinez-Frias J, Aceves SM, Smith JR, Brandt H. Thermodynamic analysis of zero-atmospheric emissions power plant. ASME J Eng Gas Turbines Power 2004;126:2-8.

[16] Ishida M, Jin H. $\mathrm{CO}_{2}$ Recovery in a novel power plant system with chemical-looping combustion. J Energy Convers Manage 1997; 38(19):187-92.

[17] Ishida M, Jin H. A new advanced power-generation system using chemical-looping combustion. Energy 1994;19:415-22.

[18] Naqvi R, Bolland O. Off-design evaluation of a natural gas fired chemical looping combustion combined cycle with $\mathrm{CO}_{2}$ capture. In: Proceedings of ECOS2005: 827-834, Trondheim, Norway, 2005.

[19] Griffin T, Sundkvist SG, Asen K, Bruun T. Advanced zero emissions gas turbine power plant. ASME J Eng Gas Turbines Power 2005; 27:81-5.

[20] Moller BF, Torisson T, Assadi M, et al. AZEP gas turbine combined cycle power plants - thermo-economic analysis. In: Proceedings of ECOS2005: 819-826, Trondheim, Norway, 2005.

[21] Kvamsdal HM, Jordal K, Bolland O. A quantitative comparison of gas turbine cycles with $\mathrm{CO}_{2}$ capture. Energy 2007;32:10-24.

[22] Fiaschi D, Lombardi L, Tapinassi L. The recuperative auto thermal reforming and recuperative reforming gas turbine power cycles with $\mathrm{CO}_{2}$ removal-Part I: the recuperative-auto thermal reforming cycle. ASME J Eng Gas Turbines Power 2003;125:933-9.

[23] Fiaschi D, Lombardi L, Tapinassi L. The recuperative auto thermal reforming and recuperative reforming gas turbine power cycles with $\mathrm{CO}_{2}$ removal-Part II: the recuperative reforming cycle. ASME J Eng Gas Turbines Power 2004;126:62-8.

[24] Lozza G, Chiesa P. Natural gas decarbonization to reduce $\mathrm{CO}_{2}$ emission from combined cycles-Part II: steam-methane reforming. ASME J Eng Gas Turbines Power 2002;124:89-95.

[25] Adelman ST, Hoffman MA, Baughn JW. A methane-steam reformer for a basic chemically recuperated gas turbine. ASME J Eng Gas Turbines Power 1995;117:16-23. 
[26] Abdallah H, Facchini B, Danes F, De Ruyck J. Exergetic optimization of intercooled reheat chemically recuperated gas turbine. Energy Convers Manage 1999;40:1679-86.

[27] Kesser KF, Hoffman MA, Baughn JW. Analysis of a basic chemically recuperated gas turbine power plant. ASME J Eng Gas Turbines Power 1994;116:277-84.

[28] Aspen Plus ${ }^{\mathbb{R}}$, Aspen Technology, Inc., version 11.1, 〈http://www. aspentech.com/ $>$.

[29] Dunbar WR, Lior N. Sources of combustion irreversibility. Combust Sci Technol 1994;103:41-61.

[30] Sarmiento-Darkin W, Lior N. Methodology for intrinsic exergy analysis as guide for process improvement, with a fuel droplet combustion example, ASME paper IMECE2005-80554. In: Proceedings of the IMECE2005, 2005 ASME international mechanical engineering congress and exposition, November 5-11, 2005, Orlando, FL, USA, ASME, NY.

[31] ESDU International, Selection and costing of heat exchangers. ESDU engineering data 92013. London: ESDU International; 1994.

[32] Davison J. Performance and cost of power plants with capture and storage of $\mathrm{CO}_{2}$. Energy 2007;32:1163-76.

[33] Pronske K, Trowsdale L, Macadam S, Viteri F, Bevc F, Horazak D. An overview of turbine and combustor development for coal-based oxy-syngas system. In: Proceedings of the ASME turbo expo 2006, GT2006-90816, Barcelona, Spain, 2006.

[34] Buhre BJP, Elliott LK, Sheng CD, Gupta RP, Wall TF. Oxy-fuel combustion technology for coal-fired power generation. Prog Energy Combust Sci 2005;31:283-307. 